\title{
Boomerang Effects of Sexual-Violence Prevention Messages on College Men's Attitudes
}

\author{
Caitlin Spikes, MA \\ Miglena Sternadori, PhD \\ Texas Tech University
}

\begin{abstract}
Background: Sexual assault is a serious public health problem in the U.S. Although colleges and universities receiving federal funding are required to provide sexual violence prevention and awareness programs, initiatives aimed specifically at college men remain relatively uncommon. Furthermore, assessments of the effectiveness of such programs suggest that most do not contribute to the prevention of sexual violence on college campuses.

Aim: This study investigates the prevalence and malleability of attitudes that underlie sexually violent behaviors perpetrated by self-identified heterosexual, cisgender male college students against college women.

Methods: Seventy-one self-identified heterosexual, cisgender, full-time undergraduate male students, all at low risk for committing sexual assault, participated in a pretest-posttest online experiment. They were randomly assigned to one control condition and two experimental sexual-assault-prevention interventions featuring a female or a male speaker.

Results: The experimental conditions did not have the intended effects of eliciting attitudes that would further the prevention of sexual violence on college campuses. The experimental conditions were, in fact, less effective on some measures than the control condition.

Conclusions: The findings suggest a boomerang effect, which refers to a persuasive outcome opposite to the desired one. Previous research has pointed to boomerang effects of sexual-assault prevention programs among high-risk men. The results of this study suggest a boomerang effect is also evident among college men at low risk for committing sexual assault.
\end{abstract}

Submitted 1 October 2018: accepted 17 October 2018

Keywords: college men, sexual assault, prevention, boomerang effect

Sexual assault is an increasingly serious public health problem in the U.S., with "far-reaching consequences to the victims" (Orchowski \& Gidycz, 2015, p. 803). Although all colleges and universities receiving federal funding are required to provide rape prevention and awareness programs (Malamuth, Huppin, \& Linz, 2018), initiatives aimed specifically at college men remain relatively uncommon. A report prepared for the White House Task Force to Protect Students from Sexual Assault in 2014 notes efforts to engage men at 32 colleges and universities receiving funding from the U.S. Department of Justice Office of Violence against Women (OVW, DeGue, 2014, p. 27). The initiatives include programs such as "Walk a Mile in Her Shoes," "Coaching Boys into Men," "Beyond Tough Guise" chapters of Men against Rape, V-Men, and Men of Strength, "Bro Code" workshops, and presentations at freshman orientations. Among these programs, only "Coaching Boys into Men" (11 sessions of 10-15 minutes for college 
athletes) was identified by the OVW as potentially effective (DeGue, Valle, Holt, Massetti, Matjasko, \& Tharp, 2014). The White House report also lists eight colleges with men's programs that have not been reviewed by the OVW (DeGue, 2014, p. 31).

This study investigates the prevalence and malleability of attitudes that underlie sexually violent behaviors perpetrated by self-identified heterosexual, cisgender male college students against college women. ${ }^{1}$ This focus is not intended to suggest that college women never initiate nonconsensual sexual interactions. Rather, it reflects statistical trends indicating that college men are more likely than college women to be perpetrators of sexual violence. For example, in a sample of over 1,600 U.S. male college students surveyed between 1990 and 1995 and between 2008 and 2011, 10.8\% reported committing at least one rape between the age of 14 and the end of college (Swartout et al., 2015). The study aims to contribute to the literature by collecting and analyzing contemporary data on the prevalence of undergraduate college men at high risk for committing sexual assault and by assessing the efficacy of two short interventions (TED talks) in reducing any sexual-violence-supportive attitudes. The following section reviews the relevant literature and summarizes the theoretical foundation for the malleability of attitudes.

\section{BACKGROUND}

For the purposes of this manuscript, sexual violence is defined as “physical sexual acts perpetrated against a person's will or where a person is incapable of giving consent due to the victim's use of drugs or alcohol ... [or] .... an intellectual or other disability" (U.S Department of Education, 2011, p. 1). Sexual violence in this definition includes rape, sexual assault, sexual battery, and sexual coercion. Although state laws vary, rape is generally defined as an act of forced or coerced oral, anal, or vaginal penetration (Sable, Davis, Mauzy, \& Gallagher, 2006), regardless of the sex of the perpetrator and the victim. As of 2018, Georgia is the only state that defines rape as non-consensual "penetration of the female sex organ by the male sex organ" (RAINN, 2018a, n.p.). Sexual assault is defined as "sexual contact or behavior that occurs without explicit consent of the victim" (RAINN, 2018b, n.p.).

Sexual violence exists within a sociocultural environment in which female victims often feel that they "deserve" the assault and fear discrimination due to reporting. If and when they do report, they tend to do so only by the encouragement of a friend or a family member (Ahrens, Campbell, Ternier-Thames, Wasco, \& Sefl, 2007). The Bureau of Justice Statistics estimates that only 23\% of rapes and sexual assaults in 2016 were reported (Bureau of Justice Statistics, 2017). Alcohol plays a role in nearly half of assaults because men drinking with women are more likely to misperceive sexual intent and exert pressure for sex, while the women blame themselves, believing their alcoholimpaired judgment made them prone to poor decision making (Abbey, 2002).

While colleges and universities do not have accurate data on the prevalence of campus sexual assault because up to $95 \%$ of sexual violence incidents may not be reported (McCaskill, 2014), anonymous surveys have suggested the scope of the issue. For example, Orchowski and Gidycz (2015) found that 82\% of 374 undergraduate women living in residence halls had experienced unwelcome sexual contact, usually while under the influence of drugs or alcohol.

\footnotetext{
${ }^{1}$ References to male/female students or college men/women in this paper are limited to cisgender individuals due to the shortage of research on sexual violence perpetrated or experienced by transgender college students. One study reported a $24 \%$ incidence of sexual assault among sexual-minority, including transgender, college students over a sixmonth period (Edwards et al., 2015), but no research appears to exists on potential transgender perpetrators in college populations.
} 
The Rape, Abuse, and Incest National Network reports that "sexual violence has fallen by half in the last 20 years" (RAINN, 2018c). More visibly, the \#MeToo movement, which began in October 2017 (on the heels of an earlier hashtag campaign, \#BeenRapedNeverReported) brought the prevalence of sexual violence to the forefront of public attention (Mendes, Ringrose, \& Keller, 2018). In 2018, former film producer and serial sexual predator Harvey Weinstein was indicted on rape charges (Izadi, 2018), and the once-legendary entertainer Bill Cosby was found guilty of drugging and sexually assaulting at least one of the over 60 women who have accused him of sexual assault, resulting in a sentence of at least three years (Bowley \& Coscarelli, 2018). These examples suggest increased awareness of sexual assault.

Literature on sexual violence interventions has revealed the alarming possibility that some interventions may backfire by increasing the risk of sexual assault, especially among men who are already deemed to be at high risk (Malamuth et al., 2018). While Malamuth and colleagues did not test the effectiveness of any specific interventions, their review of the literature indicated boomerang effects have been observed after exposure to messages aimed at reducing unhealthy behaviors or reducing aggression and violence. For example, Bosson, Parrott, Swan, Kuchynka, and Schramm (2015) found that exposure to normative messages that "press for protective or egalitarian treatment of women yields higher levels of antisocial behavior toward women" among men who score high in sexism (p. 10). Malamuth et al. (2018) thus call for additional research and suggest the following explanation for the lack of attention to the problem: "...if administrators are aware of the dangers of boomerang effects, they may be reluctant to conduct evaluations lest it is revealed that their current interventions are not working and actually potentially doing more harm than good" (p. 23). A meta-analysis of over 100 studies on the effectiveness of rape prevention programs involving over 18,000 participants (half of whom were men) supported the findings of short-term effects in attitudes and awareness, but noted no resulting noticeable decrease in the incidence of sexual assault on college campuses (Anderson \& Whiston, 2005).

The goal of virtually all persuasive strategies is to change a specific set of attitudes. The degree to which such a change may occur is likely to depend on (a) participants' motivation to process the provided information and (b) specific message features, such as the speaker's characteristics, the type of appeal being made, and the quality of the arguments (Chaiken \& Troppe, 1999; Petty \& Cacioppo, 1986). Motivated audiences who perceive a topic as relevant are more likely to deliberately consider and process a persuasive message, while unmotivated or distracted audiences tend to rely on cues and heuristics. Such cognitive shortcuts may include the speaker's level of attractiveness, the receiver's perceived degree of similarity to the speaker, the speaker's use of anecdotes and humor, etc. Identification with the speaker has traditionally been considered central to persuasion (Burke, 1950). More recent research also supports identification's importance to the success of a persuasive message, especially when the message is a narrative (e.g., De Graaf, Hoeken, Sanders, \& Beentjes, 2012).

\section{METHODS}

The following research questions and hypothesis provided the direction for this study:

RQ 1: How common are sexual-violence-supportive attitudes among undergraduate college men?

H1: Participants in the two experimental conditions will show lower levels of sexual-violence-supportive attitudes than will the participants in the control condition.

H2: After exposure to the stimuli, participants in the male- speaker condition will demonstrate lower levels of sexual-violence-supportive attitudes than the female- speaker and control conditions. 
The method was a pretest-posttest online experiment, which was constructed and administered via the Qualtrics platform. Although the online administration reduced experimental control (i.e., ensuring the participants are not multitasking), this method was selected to ensure the anonymity of the participants and encourage them to give more honest answers than they might provide in a lab study. The independent variable was condition (male speaker, female speaker, control). The dependent variable was the degree to which participants' attitudes indicated support for sexual violence. The stimuli and measures were presented via the Qualtrics online platform. Participants could participate from anywhere, as long as they used an Internet-connected device and had created an account in the SONA recruitment system through which the study was administered. The median time to complete the study was 1,043 seconds, or about 17.4 minutes. The research was approved by the university's Institutional Review Board.

\section{Participants}

The participants were students recruited from a large public university in the Southwest. They received extra course credit for participation in this study, but were also offered alternative options to earn extra credit by participating in other studies or by completing an assignment unrelated to research participation. The screening questions asked them to identify their gender (male, female, other, or would rather not specify) and sexual orientation (heterosexual/ straight; homosexual/gay/lesbian; bisexual; asexual; other; or would rather not answer). Of the 152 participants who entered the study, 71 who met the screening criteria by self-identifying as full-time undergraduate students, male, and heterosexual completed it. Their median age was 22.5. A computer algorithm randomly assigned 26 of these participants to the male-speaker condition, 23 to the female-speaker condition, and 22 to the control condition.

The average political leaning $(1=$ far right, $7=$ far left $)$ was center-right $(M=3.24, S D=1.38)$. Over a third $(38 \%)$ of participants identified as "middle of the road," $11.3 \%$ identified as far right, and none identified as far left. Over a third (35.2\%) reported that their parents' annual income exceeded $\$ 100,000$. Age, political leaning, and income bracket did not correlate significantly with the participants' self-reported history of sexual coercive behaviors.

\section{Stimuli}

The stimuli were three TED talks, each between 11 and 12 minutes long, delivered at regional and independently organized TED events. The choice to use video stimuli reflected the common use of video-based sexual assault prevention interventions (O'Donohue, Yeater, \& Fanetti, 2003). The speakers in the two experimental conditions were students, while the control condition speaker was a middle-aged professional woman. The experimental TED talks were identified through YouTube searches for "TED" and "sexual assault," using a filter to limit the results to videos of less than 20 minutes. The videos' length was considered because of concerns that participating college students may stop paying attention to a full-length (20 minutes) TED talk. The control condition talk was selected to match the length, with a topic that could plausibly relate to the consent form's description of the study's stated goal, which was "to understand male students' attitudes toward the prevention of sexual assault on college campuses."

The first experimental condition featured a TED talk from a man's perspective. It was titled "Re-thinking sexual assault prevention in high school and college" and delivered by John Kalin, president of Male Athletes against Violence at Colby College (TEDx Talks, 2013). The talk is 12 minutes and 4 seconds long, and has been viewed on YouTube approximately 65,000 times. As of October 2018, it has been upvoted 282 times and downvoted 44 times. 
The second experimental condition featured a TED talk from a woman's perspective. It was titled "A life of rape culture" and delivered by Brynne Thomas, a Trinity College student at the time (TEDx Talks, 2015). The talk was deemed the winning presentation in an Equity and Social Justice class. It is 11 minutes and 20 seconds long, and has been viewed on YouTube about 37,000 times. As of October 2018, the talk had been upvoted 635 times and downvoted about 1,100 times.

The control condition featured a TED talk about the art of having a conversation. This subject was not directly related to sexual assault, but was selected because it could be interpreted as tangentially relevant, given earlier research that has blamed sexual assaults, in part, on "poor communication skills" (Wood \& Jewkes, 1997, p. 45). The talk, titled "10 ways to have a better conversation," was delivered by Celeste Headlee, a radio host (TED, 2016). The talk is 11 minutes and 45 seconds long. It has been viewed on YouTube approximately 5 million times. As of October 2018, it had been upvoted about 110,000 times and downvoted about 1,500 times.

The three talks were selected in spite of the differences in their popularity and likability (as measured by viewing times, upvotes, and downvotes) because they appeared to be the best available matching stimuli in terms of length, identical format (TED stage), speaker gender (male and female for the experimental condition), and topic. The alternative, to create our own audiovisual stimuli for better experimental control, was not available due to limited resources.

\section{Measures and Procedure}

Qualifying participants were first asked a series of 10 questions representing the coerce subscale of Zurbriggen's (2000) Aggressive Sexual Behavior Scale to measure participants' history of sexual coerciveness (Table 1). The measure was administered online. Some of Zurbriggen's items (p. 565) were slightly modified to make them apply to a wider range of sexually coercive situations, therefore strengthening the validity of the instrument. For example, the item "I have gotten a little drunk and forced the person I am with to have sex with me" was modified to "Under the influence of alcohol, I have forced the person I am with to have sex with me." The goal of this modification was to extend it to situations in which not only the perpetrator but also the victim may be under the influence of alcohol. In another modification, Zurbriggen's item "I have belittled someone's manhood or womanhood in order to get them to sleep with me" was changed to "I have belittled someone in order to get them to sleep with me" because this arguably extends to a wider range of situations. In a third example, "I have gotten someone drunk or high so they would be less able to resist my advances" was changed to "I have gotten someone drugged or drunk so they would be less able to resist my sexual advances," with the goal of including situations in which the perpetrator uses sedatives (Quaaludes, Rohypnol, etc.) that do not result in an experience perceived as a "high." The variance on this measure was relatively limited. Individual participants' mean level of coerciveness ranged from 4.35 to 7 , where 7 indicated the lowest possible risk.

Following exposure to the persuasive message in each of their respective conditions, participants were asked 11 additional questions. The second measure was also administered online. These items (see Table 2) were authorconstructed by first, summarizing the ideas expressed by the speakers in the TED talks presented in the two experimental conditions. This approach aimed to ensure that the items measured what they intended to measurethe effects of the TED talks — therefore improving the validity of the measure. Second, the author-constructed items combined and modified items from existing inventories, such as the updated Illinois Rape Myth Acceptance Scale (McMahon \& Farmer, 2011). The goal of the posttest questions was to assess the participants' (a) basic understanding 
of sexual assault; (b) likelihood of bystander intervention (Banyard, Plante, \& Moynihan, 2005); (c) perceptions of the prevalence of sexual assault in their social environment; and (d) perceptions of the persuasive message. Because the posttest questions evaluated the potential effect of each TED talk on participants' attitudes, for purposes of validity they had to be different from the pretest measure, which evaluated only the frequency of past sexually coercive behaviors. Due to the relatively low internal consistency of the resulting scale $(\alpha=.72)$, as well as the low internal consistency for the subscales (Table 2 ), the post-test items were analyzed both individually and together.

\section{RESULTS}

RQ1 asked how common sexual-violence-supportive attitudes are among undergraduate college men. Per Zurbriggen's (2000) categorization, all of this study's participants were at low risk of committing sexual assault because they scored within $40 \%$ of the lowest-risk score (corresponding to between 4.2 and 7). Thirty-five participants (49.5\%) scored at 7, indicating the lowest possible risk. The median was 6.9, and the mode was 7. The lowest score was 4.35.

Statistical significance for the two hypotheses in this study were determined at a $p<.10$ level, which is used in exploratory studies (Cryder, Kilmer, Tedeschi, \& Calhoun, 2006; Narayanan, Olk, \& Fukami, 2010); H1 stated that participants assigned to either of the two experimental conditions will indicate higher concern about sexual assault combined with lower acceptance of rape myths than the participants in the control condition, as measured by the posttest mean. Condition had a marginally statistically significant effect on the mean of the participants' self-reported scores on the 11 posttest items combined, $F(2,68)=2.98, p=.06$. Scheffe posthoc tests indicated a statistically significant difference only between the female-speaker and the control condition, in a direction opposite to the one hypothesized. The participants in the control condition indicated a higher likelihood of bystander intervention and a stronger intent to ensure consent before their next sexual act, among other findings (Table 2). The results were opposite the hypothesized direction. H1 was, therefore, not supported.

H2 stated that the participants in the male-speaker condition will demonstrate lower levels of sexual-violencesupportive attitudes than the female- speaker and control conditions. The results shown in Table 2 indicate that there was a statistically significant difference between the male- and female-speaker conditions for only one posttest item, "I will be more aware about assuring consent before pursuing my next sexual act." The difference was in the hypothesized direction, in that the male-speaker condition produced a higher level of agreement (though for just one item) than the female-speaker condition. H2 was therefore partially supported.

\section{DISCUSSION}

This study sought to investigate the prevalence of sexual-violence-supportive attitudes among college men and the potential effects of messages that were critical of sexual violence. The results indicated that, contrary to earlier findings (Malamuth et al., 1991; Schewe \& O’Donohue, 1996), none of the participants in this study could be classified as being at medium or high risk of committing sexual assault. The perfect low-risk score (7) registered by half of the participants in responding to the pretest questions about coercive attitudes and behaviors in heterosocial interactions suggests many college men in our sample were aware of rape myths and actively resisted them. These findings may be explained at least in part by the recent visibility of high-profile rape and sexual assault cases due to the \#Me'Too movement, which may have raised participants' awareness of sexual violence or the social desirability of being seen as sexually non-violent. 
The results also indicated that the experimental conditions did not have the expected effects. The experimental treatments were, in fact, less effective on some measures than the control condition. These unexpected findings align with previous findings of a boomerang effect of sexual assault programs aimed at men, as summarized by Malamuth et al. (2018). A boomerang effect refers to a persuasive outcome opposite to the desired one, and has been argued to occur due to the triggering of negative emotions, weak argumentation, and large distance between communicator and listener's positions (Hovland, Janis, \& Kelley, 1953).

Byrne and Hart (2009) proposed a theoretical model of the boomerang effect arguing that it can be explained by two potential mechanisms: message receivers either do not process the message as intended, or they do, but "then resist complying with it" (p. 3). A study investigating why elementary school children exhibited a boomerang effect after an anti-aggression media literacy intervention found the effect was due to being primed by violent clips rather than by reactance to the message (Byrne, Linz, \& Potter, 2009). However, in the case of sexual assault prevention interventions, Malamuth et al. (2018) argue that any boomerang effects would reflect counterarguing and "hostility reactance" (p. 20), suggesting that psychological reactance theory is at the foundation of the boomerang effect. The theory posits that when "perceived behavioral freedoms are threatened or reduced," the message receivers-especially adolescents and young adults — are more likely to engage in source derogation and rejection of the persuasive message (Miller, Lane, Deatrick, Young, \& Potts, 2007, p. 219). Restoring one's freedom may, therefore, take the form of personally or vicariously performing (or intending to perform) the threatened behavior, resulting in a boomerang effect. While Malamuth et al. (2018) specifically caution about boomerang effects from sexual assault prevention messages among men at high risk of perpetrating sexual violence, this study suggests similar effects may exist among low-risk men as well, possibly because prevention interventions may be perceived as conformity measures.

\section{THEORETICAL AND PRACTICAL IMPLICATIONS}

The findings suggest that psychological reactance theory is applicable to the efficacy of sexual-violence-prevention messages. Previous studies have indicated that such reactance has been elicited by numerous public-health and prosocial campaigns, and that it combines negative cognition with anger (Dillard \& Shen, 2005). The case of hostile reactance to rape-prevention intervention programs offers the opportunity to expand reactance theory across contexts. Considering Dillard and Shen's (2005) argument that reactance results from a combination of negative cognition and anger, future research should investigate whether reactance to sexual assault prevention messages may reflect perceived threats not only to one's free choice, but also aspects of identity (i.e., masculinity).

In terms of practical implications, the arguments of Malamuth et al. (2018) and the findings of this study suggest a need for careful pretesting of any potential intervention programs aimed at undergraduate college men. To avoid reactance, Miller et al. (2007) have proposed using a symbolic restoration of freedoms by including a postscript message reminding listeners that the choice of how to behave is ultimately theirs. In the case of violence-prevention messages, such symbolic restoration strategy would unfortunately face a serious ethical challenge because endorsing a potential perpetrator's freedom to engage in non-consensual sexual behavior would always be unacceptable. Other strategies to reduce reactance—such as using concrete language and "I" statements while avoiding so-called controlling words (i.e., "must"; "need"; "ought," and "should")—may also be worth considering.

It is important to note that in this study the male-speaker condition elicited significantly higher levels of agreement with the statement "I will be more aware about assuring consent before pursuing my next sexual act" than the femalespeaker condition. This finding suggests the possibility that identification with the speaker may moderate 
psychological reactance to some aspects of sexual-violence-prevention messages. Future research should elaborate on the contexts in which identification with the speaker may have such an effect.

\section{LIMITATIONS AND DIRECTIONS FOR FUTURE RESEARCH}

This study was limited by the relatively small number of full-time undergraduate students who completed the online study. The researcher had no access to the participants' personal information, which assured complete anonymity and a greater likelihood of an honest self-report. However, it is also possible that a small number of the participants did not, in fact, meet the criteria (i.e., college women) but completed the study nonetheless in order to obtain extra course credit. The study is also limited by the lack of pretesting of the author-constructed questions, as well as the selfselected sample and the element of possible coercion due to the promise of extra credit, even though students had alternative options to earn extra credit by participating in other studies or by completing an assignment unrelated to research participation. Future research should seek to balance participants' anonymity with more experimental control (lab setting and use of identical messages read by actors of different genders). Data collection across several college campuses could ensure not only a more sizeable sample, but also more generalizable findings. 


\section{REFERENCES}

Abbey, A. (2002). Alcohol-related sexual assault: A common problem among college students. Journal of Studies on Alcohol, 14(1), 118-128. https://doi.org/10.15288/jsas.2002.s14.118

Anderson, L. A., \& Whiston, S. C. (2005). Sexual assault education programs: A meta-analytic examination of their effectiveness. Psychology of Women Quarterly, 29(4), 374-388. https://doi.org/10.1111/j.1471-

6402.2005.00237.x

Ahrens, C.E., Campbell, R., Ternier-Thames, N.K., Wasco, S.M., \& Sefl, T. (2007). Deciding whom to tell: Expectations and outcomes of rape survivors' first disclosures. Psychology of Women Quarterly, 31(1), 38-49. https://doi.org/10.1111/j.1471-6402.2007.00329.x

Banyard, V.L., Plante, E.G., \& Moynihan, M.M. (2005). Rape prevention through bystander education: Final report to NIJ for grant 2002-WG-BX-0009. Retrieved from https://www.ncjrs.gov/pdffiles1/nij/grants/208701.pdf.

Bosson, J. K., Parrott, D. J., Swan, S. C., Kuchynka, S. L., \& Schramm, A. T. (2015). A dangerous boomerang: Injunctive norms, hostile sexist attitudes, and male-to-female sexual aggression. Aggressive Behavior, 41(6), 580-593. https://doi.org/10.1002/ab.21597

Bowley, G., \& Coscarelli, J. (2018, September 25). Bill Cosby, once a model of fatherhood, is sentenced to prison. The New York Times. Retrieved from https://www.nytimes.com.

Bureau of Justice Statistics. (2017, December). Criminal victimization 2016 (report NCJ 251150). Retrieved from https://www.bjs.gov/content/pub/pdf/cv16_sum.pdf.

Burke, K. (1950). A rhetoric of motives. Upper Saddle River, NJ: Prentice-Hall.

Byrne, S., \& Hart, P. S. (2009). The boomerang effect: A synthesis of findings and a preliminary theoretical framework. Annals of the International Communication Association, 33(1), 3-37. https://doi.org/10.1080/23808985.2009.11679083

Byrne, S., Linz, D., \& Potter, W. J. (2009). A test of competing cognitive explanations for the boomerang effect in response to the deliberate disruption of media-induced aggression. Media Psychology, 12(3), 227-248. https://doi.org/10.1080/15213260903052265

Chaiken, S., \& Troppe, Y. (1999). Dual-process theories in social psychology. Guilford Press.

Cryder, C. H., Kilmer, R. P., Tedeschi, R. G., \& Calhoun, L. G. (2006). An exploratory study of posttraumatic growth in children following a natural disaster. American Journal of Orthopsychiatry, 76(1), 65-69. https://doi.org/10.1037/0002-9432.76.1.65

De Graaf, A., Hoeken, H., Sanders, J., \& Beentjes, J. W. (2012). Identification as a mechanism of narrative persuasion. Communication Research, 39(6), 802-823. https://doi.org/10.1177/0093650211408594

DeGue, S. (2014). Preventing sexual violence on college campuses: lessons from research and practice (White House Task Force to Protect Students from Sexual Assault). Retrieved from http://www.nccpsafety.org/dir_apply_form/Preventing_Sexual_Violence_on_College_Campuses.pdf. 
DeGue, S., Valle, L. A., Holt, M. K., Massetti, G. M., Matjasko, J. L., \& Tharp, A. T. (2014). A systematic review of primary prevention strategies for sexual violence perpetration. Aggression and Violent Behavior, 19(4), 346-362. https://doi.org/10.1016/j.avb.2014.05.004

Dillard, J. P., \& Shen, L. (2005). On the nature of reactance and its role in persuasive health communication. Communication Monographs, 72(2), 144-168. https://doi.org/10.1080/03637750500111815

Edwards, K. M., Sylaska, K. M., Barry, J. E., Moynihan, M. M., Banyard, V. L., Cohn, E. S., ... \& Ward, S. K. (2015). Physical dating violence, sexual violence, and unwanted pursuit victimization: A comparison of incidence rates among sexual-minority and heterosexual college students. Journal of Interpersonal Violence, 30(4), 580-600. https://doi.org/10.1177/0886260514535260

Hovland, C. I., Janis, I. L., \& Kelley, H. H. (1953). Communication and persuasion: psychological studies of opinion change. Yale University Press.

Izadi, E. (2018, July 2). Harvey Weinstein indicted on new sexual assault charges, could face life in prison. The Washington Post. Retrieved from https:/ /www.washingtonpost.com.

Malamuth, N., Huppin, M., \& Linz, D. (2018). Sexual assault interventions may be doing more harm than good with high-risk males. Aggression and Violent Behavior, 41, 20-24. https://doi.org/10.1016/j.avb.2018.05.010

McCaskill, C. (2014, July 9). Sexual violence on campus. Retrieved from http://www.mccaskill.senate.gov/SurveyReportwithAppendix.pdf.

McMahon, S., \& Farmer, G. L. (2011). An updated measure for assessing subtle rape myths. Social Work Research, 35(2), 71-81. https://doi.org/10.1093/swr/35.2.71

Mendes, K., Ringrose, J., \& Keller, J. (2018). \#MeToo and the promise and pitfalls of challenging rape culture through digital feminist activism. European Journal of Women's Studies, 25(2), 236-246. https://doi.org/10.1177/1350506818765318

Miller, C. H., Lane, L. T., Deatrick, L. M., Young, A. M., \& Potts, K. A. (2007). Psychological reactance and promotional health messages: The effects of controlling language, lexical concreteness, and the restoration of freedom. Human Communication Research, 33(2), 219-240. https://doi.org/10.1111/j.1468-2958.2007.00297.x

Narayanan, V. K., Olk, P. M., \& Fukami, C. V. (2010). Determinants of internship effectiveness: An exploratory model. Academy of Management Learning \& Education, 9(1), 61-80. https://doi.org/10.5465/amle.9.1.zqr61

O’Donohue, W., Yeater, E. A., \& Fanetti, M. (2003). Rape prevention with college males: The roles of rape myth acceptance, victim empathy, and outcome expectancies. Journal of Interpersonal Violence, 18(5), 513-531. https://doi.org/10.1177/0886260503251070

Orchowski, L. M., \& Gidycz, C. A. (2015). Psychological consequences associated with positive and negative responses to disclosure of sexual assault among college women: A prospective study. Violence against Women, 21(7), 803-823. https://doi.org/10.1177/1077801215584068

Petty, R. E. \& Cacioppo, J. T. (1986). Communication and persuasion: Central and peripheral routes to attitude change. New York: Springer-Verlag. https://doi.org/10.1007/978-1-4612-4964-1

RAINN. (2018a). The laws in your state: Georgia. Retrieved from https://www.rainn.org/laws-your-state-georgia. 
RAINN. (2018b). Sexual assault. Retrieved from https://www.rainn.org/articles/sexual-assault.

RAINN. (2018c). Statistics. Retrieved from https://www.rainn.org/statistics.

Sable, M. R., Danis, F., Mauzy, D. L., \& Gallagher, S. K. (2006). Barriers to reporting sexual assault for women and men: Perspectives of college students. Journal of American College Health, 55(3), 157-162. https://doi.org/10.3200/JACH.55.3.157-162

Schewe, P.A., \& O’Donohue, W. (1996). Rape prevention with high-risk males: Short-term outcome of two interventions. Achieves of Sexual Behaviors, 25(5), 455-471. https://doi.org/10.1007/BF02437542

Swartout, K. M., Koss, M. P., White, J. W., Thompson, M. P., Abbey, A., \& Bellis, A. L. (2015). Trajectory analysis of the campus serial rapist assumption. Journal of the American Medical Association Pediatrics, 169(12), 1148-1154. https://doi.org/10.1001/jamapediatrics.2015.0707

TED. (2016, March 8). 10 ways to have a better conversation | Celeste Headlee [Video file]. Retrieved from https://www.youtube.com/watch?v=R1vskiVDw14.

TEDx Talks. (2013, May 21). Rethinking sexual assault prevention in high school and college: John Kalin at TEDxColbyCollege [Video file]. Retrieved from https://www.youtube.com/watch?v=dRuPFmo15Tk.

TEDx Talks. (2015, May 31). A life of rape culture | Brynne Thomas | TEDxYouth@TCS [Video file]. Retrieved from https://www.youtube.com/watch?v=oYppe9kyUxY.

U.S. Department of Education. (2011, April 4). "Dear colleague” Letter 1. Retrieved from http://www2.ed.gov/about/offices/list/ocr/letters/colleague-201104.pdf.

Wood, K., \& Jewkes, R. (1997). Violence, rape, and sexual coercion: Everyday love in a South African township. Gender \& Development, 5(2), 41-46. https://doi.org/10.1080/741922353

Zurbriggen, E. L. (2000). Social motives and cognitive power-sex associations: Predictors of aggressive sexual behavior. Journal of Personality \& Social Psychology, 78(3), 559-581. https://doi.org/10.1037/00223514.78.3.559

Address author correspondence to:

Miglena Sternadori, PhD

Texas Tech University

College of Media \& Communication, Box 43082

Lubbock, TX 79409

miglena.sternadori@ttu.edu

\section{Author acknowledgments}

We wish to thank Dr. Meredith Wallace Kazer and the anonymous reviewers for their constructive feedback. 


\section{APPENDIX}

Table 1

Items measuring participants' bistory of sexual aggression through the "coerce" subscale of the Aggressive Sexual Behavior Scale (Zurbriggen, 2000)

Item
$(1=$ strongly agree, $7=$ strongly disagree $)$

Coerciveness

$6.67(.55)$

$(\alpha=.81)$

Under the influence of alcohol, I have forced the person I am with to have sex with me.

$6.87(.55)$

I have become verbally and/or physically aggressive when they would not surrender to my $6.79(.77)$ need for sex.

I have given someone the silent treatment when they would not have sex with me.

$6.20(1.50)$

I have gripped someone tightly in anger when they were not giving me the sexual response I $6.75(.80)$ wanted.

I have belittled someone in order to get them to sleep with me.

$6.77(.62)$

I have threatened to end a relationship if my partner would not have sex with me.

I have told someone I was making out with that they couldn't stop and leave me frustrated 6.61 (1.06) without having sex.

I have told someone that their refusal to have sex with me was changing the way I felt about $6.64(.97)$ them.

I have gotten someone drugged or drunk so they would be less able to resist my sexual 6.89 (.46) advances.

I have dated someone younger than me because I thought it would be easier to get them to 6.56 (1.23) give me what I wanted sexually.

Table 2

Post-Message-Exposure Items

\begin{tabular}{|c|c|c|c|c|c|}
\hline $\begin{array}{l}\text { Item } \\
(1=\text { strongly agree, } 7=\text { strongly disagree })\end{array}$ & $\begin{array}{l}\text { Female } \\
\text { Speaker } \\
M(S D)\end{array}$ & $\begin{array}{l}\text { Male Speaker } \\
M(S D)\end{array}$ & $\begin{array}{l}\text { Control } \\
M(S D)\end{array}$ & $\begin{array}{l}F \\
(2,68)\end{array}$ & $p$ \\
\hline $\begin{array}{l}\text { Beliefs about sexual assault and consent } \\
(\alpha=.66)\end{array}$ & $2.67(1.19)$ & 2.27 (1.11) & $2.36(1.31)$ & .74 & .48 \\
\hline $\begin{array}{l}\text { Pushing someone to have sex when they do not feel like } \\
\text { it is always wrong, no matter the circumstances. }\end{array}$ & $2.30(2.16)$ & $1.62(1.44)$ & $2.09(2.27)$ & .80 & .45 \\
\hline $\begin{array}{l}\text { Pushing someone to do any sexual act that they do not } \\
\text { want to do is rape. }\end{array}$ & $2.30(1.94)$ & $2.23(1.48)$ & $1.55(1.34)$ & 1.54 & .22 \\
\hline $\begin{array}{l}\text { It is not the responsibility of women to prevent sexual } \\
\text { harassment and assault. }\end{array}$ & $3.41(1.92)$ & 3.28 (1.97) & $3.82(2.15)$ & .45 & .64 \\
\hline $\begin{array}{l}\text { I will be more aware about ensuring consent before } \\
\text { pursuing my next sexual act.* }\end{array}$ & $2.74(1.32)^{\mathrm{a}}$ & $2.00(1.10)^{\mathrm{b}}$ & $2.00(1.35)^{\mathrm{b}}$ & 2.71 & .07 \\
\hline
\end{tabular}




\section{Likelihood of bystander intervention*}

$(\alpha=.13)$

If I observe a friend trying to coerce of physically force $1.70(.77)$ someone to have sex, I would tell him to stop it.

If I observe a friend trying to coerce of physically force $2.91(1.68)^{\mathrm{a}}$ someone to have sex, and if he does not stop it when I ask him to, I would call the police.*

\section{Perception of prevalence and significance}

$(\alpha=.43)$

Prevention of sexual assault on college campuses is of the utmost importance.*

Sexual assault is a serious problem at [university where the study was conducted].

\section{Perception of prevention message*}

$(\alpha=.17)$

I believe the contents of this TED talk reflect the reality of my surroundings.

This TED talk has made me rethink how I view sexual 3.83 (1.70) assault.

The contents of this TED talk were biased (r).*

For all items $(\alpha=.72)$

\section{$2.30(1.02)^{\mathrm{a}} \quad 2.14(1.05)^{\mathrm{a}, \mathrm{b}}$}

$1.58(1.33)$

$1.32(.72)$

.84

.44

$2.76(1.81)^{\mathrm{a}}$

$1.95(1.09)^{\mathrm{b}}$

$3.00(1.07)$

$2.69(1.01)$

$2.55(.67)$

1.39

.26

$2.04(1.11)^{\mathrm{a}}$

$1.85(1.26)^{\mathrm{a}, \mathrm{b}}$

$1.23(.43)^{\mathrm{b}}$

3.95

.02

$3.96(1.43)$

$3.54(1.27)$

$3.86(1.21)$ .70

.50

$3.28(1.01)^{\mathrm{a}}$

$3.05(.66)^{a}$

$2.53(.77)^{\mathrm{b}}$

4.85

.01

$2.91(1.20)$

$2.69(1.12)$

2.18 (1.18)

2.32

.11

$3.04(1.37)$

3.44 (1.44)

1.68

.19

$3.09(1.47)^{\mathrm{a}}$

$3.42(1.39)^{\mathrm{a}}$

$1.95(1.56)^{\mathrm{b}}$

6.35

.00

$2.83(.78)^{\mathrm{a}} \quad 2.54(.75)^{\mathrm{a}, \mathrm{b}}$

$2.31(.60)^{b}$

2.98

.06

Note. Asterisks denote items for which there were statistically significant differences between conditions at the $p<.10$ level. Each superscript letter denotes values that do not differ significantly from each other in the same row, as determined by Scheffe posthoc tests. 